\title{
International Symposium on Practice as Research (ISPaR) (Controversies, Challenges, Conceptualisations East-West Perfectives)
}

Dr (CAND). Asep Hidayat Wirayudha, M. Ed. Indonesia Institute of the Arts Yogyakarta

On 4-6 October 2017 the Hongkong Academy of Performing Arts held the International Symposium on Practice-As-Research (ISPaR) with the theme "Controversial, Challenges, Conceptualisations: East-West Perspective". This new paradigm in the last twenty years has been widely discussed by academics as an offer to the possibilities of the worldview of the arts as a product of knowledge. The blowing of this paradigm is particularly strong and exciting today, especially in Asian countries, both by academics and artists who want to apply to their artistry. The thing that really caught the attention was why did PaR's attract so much attention to academics and artists in Asian countries? Surely that question becomes a hot topic at the symposium. Controversial, Challenges, Conceptualisations: East-West Perspective is still in debate to be addressed by both academics and artists to interpret and create a formulation that will become the reference of artists.

Practice as research $(\mathrm{PaR})$ in the present time is a new way of looking at the branches of art, such as Design, Theater, Music, Dance, media and television and other arts. Basically PaR is very closely related to Practice based research and Led Research where all of them are practical based research, but in principle there is still debate and different perspectives to formulate a common concept in formulating it.

Within arts and humanities departments there are ongoing debates about how to define this emerging research phenomenon, and there are a variety of models of practice research (practice-as-research, practice-based, practice-led, mixedmode research practice and practice through research), see for example screen media practice research. The potential, nature and scope for this research has been debated from the 1990s. 
Research that takes the nature of practice as its main focus is called 'practicebased' or 'Research initiated by practice. This is done by practitioners, such as artists, designers, curators, writers, musicians, teachers and others, often, but not necessarily, in doctoral research such programs have spawned new concepts and methods in the generation of indigenous knowledge.

It is important to make a clear distinction between practice-based research and pure practice. Many practitioners will say that they do 'research' as an important part of their daily practice.

As the published notes of creative practitioners show, searching for new ideas and finding new techniques for realizing ideas is an important part of daily practice, this type of research is directed towards individual-specific goals at times rather than looking to add to our shared store knowledge in a more general sense. The expert argument that the difference is that research-based practice aims to evoke a new cultural understanding that is not just a novel.

Practice-based Research is an original investigation undertaken in order to gain new knowledge partly by means of practice and the outcomes of that practice. In a doctoral thesis, claims of originality and contribution to knowledge may be demonstrated through creative outcomes in the form of designs, music, digital media, performances and exhibitions. Whilst the significance and context of the claims are described in words, a full understanding can only be obtained with direct reference to the outcomes.

Practice-led Research is concerned with the nature of practice and leads to new knowledge that has operational significance for that practice. In a doctoral thesis, the results of practice led research may be fully described in text form without the inclusion of a creative work. The primary focus of the research is to advance knowledge about practice, or to advance knowledge within practice. Such research includes practice as an integral part of its method and often falls within the general area of action research. The primary focus of this document is on practice-based research but there is much that is relevant to practice-led research also. It begins with a discussion of the basic concepts in the context of a doctoral research programme followed by a brief historical overview of the field.

The generic structure of a practice-based doctoral thesis is then outlined with a short description of the expected content of each chapter. Further sections include a discussion of the nature of knowledge in the context of doctoral research, a set of frequently asked questions, some definitions of key terms, a bibliography and web sources.

\section{PaR}

The term 'practice as research' carves out a territory for arts practice in academic environments, and refers to a broad range of research activity. Practice as research might denote a research process that leads to an arts-related output, an arts project as one element of a research process drawing on a range of methods, or a research process entirely framed as artistic practice. 
Research might start or end in arts practice, draw on arts practice as a part of its process, or be wholly integrated into the shifting forms and outputs of an arts project. Practice as research is therefore not a 'method' as such. Arts practices draw on a variety of creative methodologies that might be incorporated into interdisciplinary research projects as methodological innovations, providing new perspectives on and extending existing knowledge as well as materialising a different kind of knowledge practice. There are a number of philosophical and political drivers here. Perhaps most importantly, if we are to understand the role, processes and function of cultural practice more generally, it is important to be able to explore through doing. Making art is an important means of understanding art and other kinds of cultural practice. Furthermore, an art-making process can generate new insights and perspectives relevant to understanding a diverse range of social and cultural phenomena - identity, community, narrative and testimony, transformation, space and time ... and so on.

Practice as research, in any disciplinary area, privileges action as a methodological imperative. In the arts, practice as research involves artist-researchers exploring, testing and extending a diverse range of creative methodologies and working across diverse contexts - exploring the relationship of creative interventions to both making and understanding the world. The outcomes of practice as research are multiple - insights into arts processes, understandings of a range of social and cultural phenomena, new kinds of artistic products, outcomes or relationships. Importantly, practice as research may never include the action of writing anything down - it may never clearly articulate a research 'question', it is open to and uses sense, sensation and intuition as part of knowledge making, and may not lead to academic publication in the conventional sense.

Szeto, Loh, Leong, Chow \& Tang, they discuss How Does PaR benefit performers \& Pedagogies. The topic of the discussion was very interesting to the participants considering the symposium participants from various professions including educators, artists and other. Certainly not easy to understand about the paradigm of practice as research applied to the two professions above, let alone this paradigm brought to the academic order of course there is still debate methods and aesthetics especially in Asia that must have agreement with the academics. For instance PaR is used as a reference as an academic framework that will become a product of science, new problems will arise especially in content and standardization, it must be discussed more thoroughly in determining the tips to be used as a formulation in practice-based research.

Perspective as a practical, according to Tang Will a professional (musician, composer,) be a researcher? alau how the results of his research? is it scientifically justified and accountable? then what if a composer makes a musical work converted into academic area? musicians, composers is essentially a researcher for himself, the rest how both can formulate his ideas into a useful study for themselves and others. 
Barbara Bolt Practice-led research is a burgeoning area across the creative arts, with studio-based doctorates frequently favoured over traditional research. Yet until now there has been little published guidance for students embarking on such research. This is the first book designed specifically as a pedagogical tool and is structured on the model used by most research programmes. A comprehensive introduction lays out the book's framework and individual chapters provide concrete examples of studio-based research in art, film and video, creative writing and dance, each contextualised by a theoretical essay and complete with references. More than a handbook, the volume draws on thinkers including Deleuze, Bourdieu and Heidegger in its examination of the relationship between practice and theory, demonstrating how practice can operate as a valid alternative mode of enquiry to traditional scholarly research. Taking pains to elaborate methodologies, contexts and outcomes, and emphasising the process of enquiry and its relationship to the research write-up or exegesis, this is an indispensable tool for educators and students.

Frans de Ruiter Further has a different perspective on Research in and Through Artistic practice, How do 'artistic researchers' articulate what cannot be written? How do they oscillate from style to style, from rule to exception and from exception to rule again? What qualifies as a $\mathrm{PhD}$, when it is partly based on a composition or an exhibition? What if the text itself is a website, instead of a printed thesis? These and other questions surround the emerging field of artistic research in Europe. It was discussed at the symposium on the last day.

Batty \& Kerrigen Screen production research is the study of creation of audio visual work that is disseminated on/with screen and can include theory - driven practice that use the screen to "do" research (e.g, research Led practice), and systematic reflection upon a production to gain rigorous insights into how a work was made -(e.g, practice- led research). The term "screen production" has emerged through Australian scholarship-elsewhere, for example, it is known as screen or media practice, filmmaking or video production-and its antecedence come about through a combination of film and television industry and the academy. In line with technological developments that made it possible to create and distribute work online and via mobile media, the Australian industry embraced the term "Screen" in 2008 with the establishment of screen Australia, the national funding body for screen works. The screen Australia act 2018 defines screen production and 'as aggregate of images, or of images and sound, embodied in any material that can be viewed.

The last day of the Symposium concludes with a very good musical performance by students of the Hongkong Academy performance department playing the quintet compositions No. 2 opus 77 by Antonin Dvorak. 